\title{
EFFECT OF VITAMIN E SUPPLEMENTATION ON PLASMA MEMBRANE FUNCTIONAL INTEGRITY IN SURTI BUCK SEMEN PRESERVED AT REFRIGERATION TEMPERATURE
}

\author{
M. A. PANDOR ${ }^{1 *}$, N. F. CHAUDHARI ${ }^{1}$, L. C. MODI ${ }^{1}$, M. JANMEDA ${ }^{2}$, \\ W.V. DINIZ ${ }^{1}$ AND D. KUMAR ${ }^{1}$ \\ ${ }^{1}$ Department of Veterinary Gynaecology and Obstetrics, College of Veterinary Sc. and A. H., Navsari \\ Agricultural University, Navsari- 396 450, Gujarat, India \\ ${ }^{2}$ Department of Animal Genetics and Breeding, College of Veterinary Sc. and A. H., Navsari \\ Agricultural University, Navsari- 396 450, Gujarat, India
}

\begin{abstract}
The present research work was carried out on four Surti bucks maintained under All India Coordinated Research Project (AICRP) on Goat at Livestock Research Station, Navsari Agricultural University, Navsari during December 2019 to March 2020 with the objective to evaluate the effect of vitamin E supplementation in tris egg yolk citrate extender on plasma membrane functional integrity in Surti buck semen preserved at refrigeration temperature. The pooled semen from all four bucks was diluted with the tris egg yolk citrate extender to make a final concentration of $200 \times 10^{6} \mathrm{sperm} / \mathrm{mL}$. The diluted semen was divided into five equal aliquots and each aliquot was treated with 0 mM (Control), 1 mM (T1), $2 \mathrm{mM}$ (T2), $3 \mathrm{mM}$ (T3) and $4 \mathrm{mM}(\mathrm{T4})$ of vitamin $\mathrm{E}$ and preserved at refrigeration temperature $\left(4-5^{\circ} \mathrm{C}\right)$ up to 48 hours to access the plasma membrane functional integrity at $0,24,36$, and 48 hours. The significantly $(p<0.01)$ highest percentage of hypo osmotic swelling (HOS) reacted and lowest percentage of HOS non-reacted sperm count (\%) irrespective of preservation time was found in $\mathrm{T} 3(73.63 \pm 0.6$ and $26.38 \pm 0.6)$ followed by control $(68.47 \pm 0.9$ and $31.53 \pm 0.9)$, $\mathrm{T} 1(67.89 \pm 0.85$ and $32.11 \pm 0.85)$, $\mathrm{T} 4(66.53 \pm 0.67$ and $33.47 \pm 0.67)$ and $\mathrm{T} 2(63.97 \pm 0.93$ and $36.03 \pm 0.93)$ groups. It can be concluded from the present study that plasma plasma membrane integrity of Surti buck semen was well maintained at refrigerated temperature up to 48 hours when extended with $3 \mathrm{mM}$ of vitamin $\mathrm{E}$.
\end{abstract}

Key words: HOS, Plasma membrane functional integrity, Sperm, Surti Buck, Vitamin E

\section{INTRODUCTION}

The goat is considered to be meticulously related to the sheep as a member of family Caprinae. India has an outstanding count of 148.88 million goats contributing $27.7 \%$ of the livestock population during the year 2019 in total livestock population (20th Livestock census, 2019). In Gujarat, the total goat population was 48.6 lakh and out of them 41.4 lakh were females. Surti goats are gifted with capacity to abide adverse climate and can be reared for milk and meat purpose. They offer main source of revenue to the poor farmers colonized around the south Gujarat region.
Artificial insemination turns out to be widely used technique for breeding goat and sheep (Foote, 2002), which requires rapid cooling, maintenance of motility, viability, plasma membrane integrity and several other parameters. The major drawback is the reduction in the quality of semen during freezing and thawing. Egg yolk has proven beneficial as a cryoprotectant of the sperm plasma membrane and acrosome against cold-shock, in association with the other components (Amirat et al., 2004). Cryopreservation can induce an increased rate of lipid peroxidation in the sperm plasma

${ }^{*}$ Corresponding Author 
membrane, causing an overall increase in the concentration of oxygen radicals (Baumber et al., 2003). The reactive oxygen species (ROS) produced during cryopreservation leads to reduce post-thaw motility, viability, membrane integrity, antioxidant status, fertility and sperm functions (White, 1993; Zhao and Buhr, 1995; Aitken et al.,1998; Bilodeau et al., 2001). Thus, to minimize the deterioration during cryopreservation antioxidants are added as cryoprotectants.

Vitamin E is a major scavenger of lipid peroxyl and alkaoxyl radicals and demonstrated to be having a protective effect during semen storage (Tariq et al., 2015). Vitamin E plays an important role as an antioxidant to prevent the lipid peroxidation of biomembranes and helps in cryopreservation of semen, thus the stored semen can easily be used in artificial insemination. Vitamin $\mathrm{E}$ has a preservative effect in Tris-citrate egg yolk (TEYC) extender for cryopreserved canine spermatozoa (Michael et al., 2007). The $\alpha$-tocopherol acetate, an analogue of Vitamin E, when used in tris-citric acid extender on cryopreserved Sahiwal bull semen reported higher values for HOS reacted sperm count (Batool et al., 2012).

\section{MATERIALS AND METHODS}

Collection of semen and its processing: Total four healthy Surti bucks above 1 years $(1.25-$ 1.3 years) of age maintained under All India Coordinated Research Project (AICRP) on Goat at Livestock Research Station, Navsari Agricultural University, Navsari, Gujrat were selected for the study. The selected bucks were regularly maintained under proper healthy and hygienic conditions and well-fed. The selected bucks were housed in a common covered pen and separated from females. The bucks were trained to donate the semen in artificial vagina using female as a dummy. After completion of the training period, semen was collected regularly by artificial vagina twice a week from each buck up to 8 weeks. Total 64 semen ejaculates (16 from each buck) were collected. Before semen collection, one false mount was given to the buck on female dummy secured in travis. Buck apron was applied to the buck to prevent touching of penile part to the hind part of dummy. The ejaculates were obtained in sterilized graduated glass tubes and transferred to the laboratory within 10 minutes. To eliminate individual buck variability and increase semen quantity, all the ejaculates were pooled during each semen collection. The pooled semen was diluted with tris egg yolk citrate extender to make a final concentration of $200 \times 10^{6} \mathrm{sperm} / \mathrm{mL}$. The diluted semen was evaluated for initial sperm motility and semen samples with $\geq 70 \%$ motility were considered for further processing.

Experimental groups: To evaluate the effect of vitamin $\mathrm{E}$ supplementation in tris egg yolk citrate extender on sperm motility the extended semen was divided into five equal aliquots and each aliquot was supplemented with $0 \mathrm{mM}$ (control), $1 \mathrm{mM}$ (T1), $2 \mathrm{mM}$ (T2), $3 \mathrm{mM}$ (T3) and $4 \mathrm{mM}$ (T4) vitamin E. The semen sample treated with different concentration of vitamin $\mathrm{E}$ was preserved at refrigeration temperature up to 48 hours. In present experiment $\alpha$-tocopherol phosphate disodium salt (Sigma Aldrich), a water-soluble analogue of vitamin $\mathrm{E}$ was used as semen additive having molecular weight $554.65 \mathrm{~g} / \mathrm{mol}$.

Plasma membrane functional integrity: To evaluate the plasma membrane functional integrity of spermatozoa, hypo osmotic swelling test (HOST) was performed by mixing $0.1 \mathrm{~mL}$ of diluted semen with $1.0 \mathrm{~mL}$ of hypoosmotic solution. The tube containing the mixture was incubated at $37^{\circ} \mathrm{C}$ for 30 minutes. A drop of semen from the mixture placed on a clean dry glass slide and covered with cover slip. The sperms characterized by varying degrees of coiling or swelling of tail were considered to have an intact plasma membrane (HOS reacted sperm) and the sperms without tail curling were considered to have damaged 
membrane (HOST non-reacted sperm). Total 200 spermatozoa were counted in different fields and percentage of spermatozoa exhibiting tail curling (reacted) was calculated.

$$
\text { HOST reacted sperm }(\%)=\frac{\begin{array}{l}
\text { No. of HOST } \\
\text { reacted sperms }
\end{array}}{\begin{array}{l}
\text { Total no. of } \\
\text { sperms counted }
\end{array}} \times 100
$$

The data pertaining to plasma membrane integrity was suitably tabulated and analyzed using R-3.3.2 software. The differences among the parameter means were performed using appropriate statistical methods viz., ANOVA, DNMRT (Duncan's New Multiple Range Test). The mean differences were considered significant at $\mathrm{p}<0.01$ and $\mathrm{p}<0.05$.

\section{RESULTS}

The initial and post-chilled HOS reacted and non-reacted sperm count of Surti buck semen supplemented with different concentrations of vitamin $\mathrm{E}$ in tris egg yolk citrate extender was monitored in all the groups at different time intervals and presented in Table 1.

The HOS reacted sperm counts $(\%)$ at 0 hours were $76.25 \pm 1.44,73.88 \pm 1.15,68.81 \pm 1.67$, $78.31 \pm 0.72$ and $71.81 \pm 0.87$ in Control, T1, T2, $\mathrm{T} 3$ and T4 groups, respectively. It was observed that the value in the T3 group was significantly $(\mathrm{p}<0.01)$ higher as compared to all treatment groups whereas, differed non-significantly with the control group. However, the HOS reacted sperm counts (\%) found at 24,36 and 48 hours post-chilling were significantly $(\mathrm{p}<0.01)$ higher in T3 $(75.5 \pm 0.8,72.19 \pm 0.71$ and $68.5 \pm 0.93$, respectively) as compared to Control $(69.94 \pm 1.29,66.19 \pm 1.10$ and $61.5 \pm 0.99$, respectively), $\mathrm{T} 1(70.31 \pm 1.19,66.00 \pm 1.29$ and $61.38 \pm 1.4$, respectively), T2 (65.63 \pm 1.69 , $62.38 \pm 1.64$ and $59.06 \pm 1.6$, respectively) and $\mathrm{T} 4$ $(68.44 \pm 0.91,64.69 \pm 0.9$ and $61.19 \pm 0.93$, respectively) groups. Further, the values of HOS reacted sperm count recorded in T3 group were significantly $(\mathrm{p}<0.01)$ higher as compared to all other groups when observed at any interval postchilling.

The corresponding overall mean values of HOS reacted sperm count $(\%)$ irrespective of various groups were reduced with increasing preservation time as $73.81 \pm 0.65,69.96 \pm 0.64$, $66.29 \pm 0.63$ and $62.33 \pm 0.64$ at $0,24,36$ and 48 hours, respectively.

Moreover, in control, T1, T2, T3 and T4 groups the HOS reacted sperm count $(\%)$ were significantly $(\mathrm{p}<0.01)$ higher at $0(76.25 \pm 1.44$, $73.88 \pm 1.15,68.81 \pm 1.67,78.31 \pm 0.72$ and $71.81 \pm 0.87$, respectively) as compared to 24 $(69.94 \pm 1.29, \quad 70.31 \pm 1.19, \quad 65.63 \pm 1.69$, $75.5 \pm 0.8$ and $68.44 \pm 0.91$, respectively), 36 $(66.19 \pm 1.10, \quad 66.00 \pm 1.29, \quad 62.38 \pm 1.64$, $72.19 \pm 0.71$ and $64.69 \pm 0.9$, respectively) and $48 \quad(61.5 \pm 0.99, \quad 61.38 \pm 1.4, \quad 59.06 \pm 1.6$, $68.5 \pm 0.93$ and $61.19 \pm 0.93$, respectively) hours post-chilling. Exceptionally, in $\mathrm{T} 1$ and $\mathrm{T} 2$ groups the HOS reacted sperm count was found non-significantly different between 0 and 24 hours of preservation time. Further, the HOS reacted sperm count recorded in various groups that differed significantly $(\mathrm{p}<0.01)$ at 24,36 and 48 hours post-chilling.

The corresponding overall mean value of HOST reacted sperm count (\%) irrespective of preservation time was significantly $(\mathrm{p}<0.01)$ highest in T3 $(73.63 \pm 0.6)$ as compared to control $(68.47 \pm 0.9), \mathrm{T} 1(67.89 \pm 0.85), \mathrm{T} 2$ $(63.97 \pm 0.93)$ and $\mathrm{T} 4(66.53 \pm 0.67)$ groups.

The values of HOS non-reacted sperm count $(\%)$ found at 0 hour were $23.75 \pm 1.44,26.13 \pm 1.15$, $31.19 \pm 1.67,21.69 \pm 0.72$ and $28.19 \pm 0.87$ in Control, T1, T2, T3 and T4 groups, respectively. It was observed that the value found in the T3 group was significantly $(\mathrm{p}<0.01)$ lower as compared to all treatment groups, whereas, differed non-significantly with the control group. However, the HOS non-reacted sperm count (\%) found at 24, 36 and 48 hours post-chilling were 


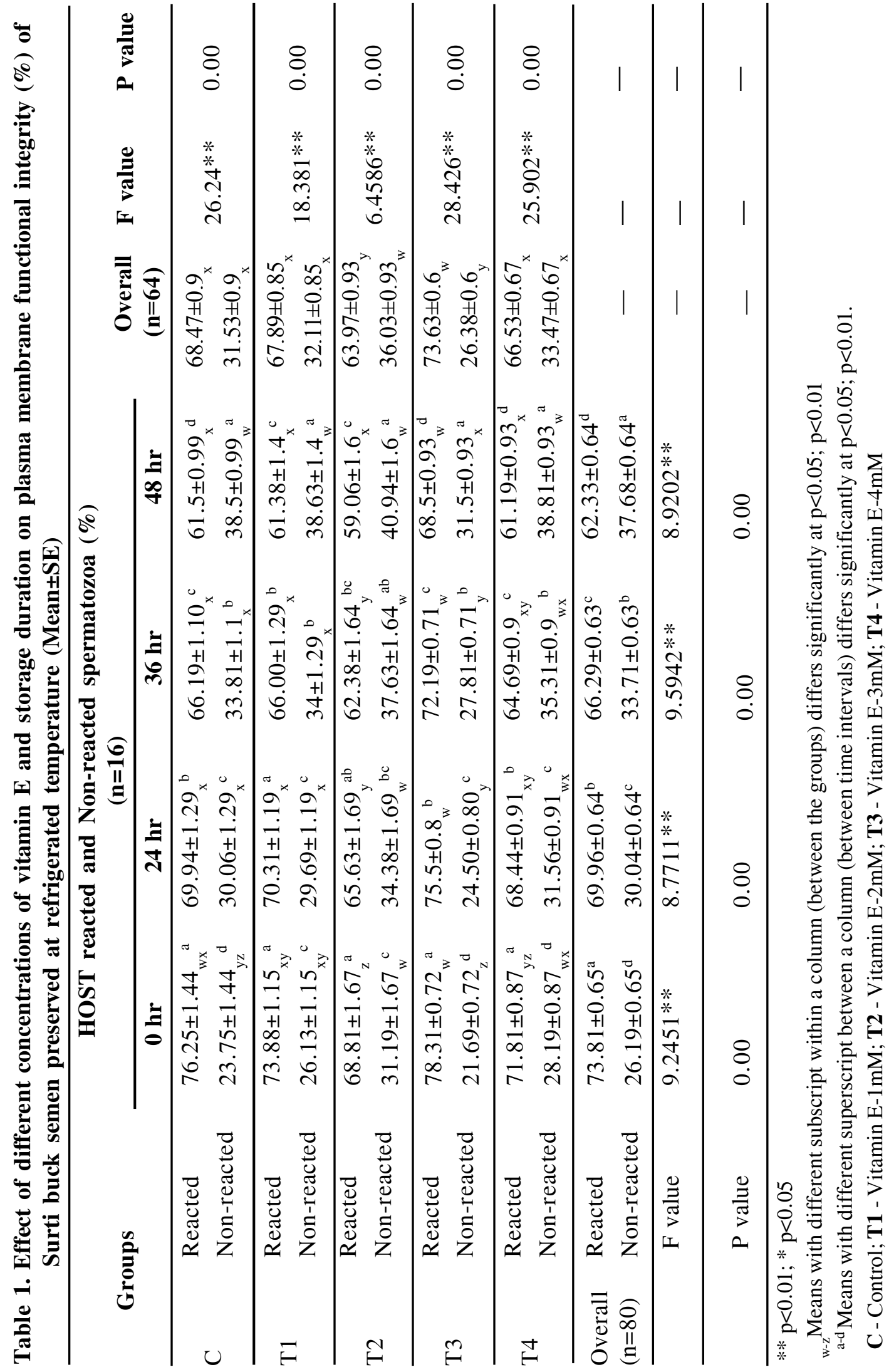


significantly $(\mathrm{p}<0.01)$ lower in T3 $(24.5 \pm 0.8$, $27.81 \pm 0.71$ and $31.5 \pm 0.93$, respectively) as compared to control $(30.06 \pm 1.29,33.81 \pm 1.1$ and $38.5 \pm 0.99$, respectively), T1 $(29.69 \pm 1.19$, $34.00 \pm 1.29$ and $38.63 \pm 1.4$, respectively), T2 $(34.38 \pm 1.69,37.63 \pm 1.64$ and $40.94 \pm 1.6$, respectively) and $\mathrm{T} 4(31.56 \pm 0.91,35.31 \pm 0.9$ and $38.81 \pm 0.93$, respectively. Further in T3 group, the values of HOS non-reacted sperm count recorded were significantly $(\mathrm{p}<0.01)$ lowest as compared to all other groups when observed at any interval post-chilling.

The corresponding overall mean values of HOS non-reacted sperm count (\%) irrespective of various groups were inclined with increasing preservation time as $26.19 \pm 0.65,30.04 \pm 0.64$, $33.71 \pm 0.63$ and $37.68 \pm 0.64$ at $0,24,36$ and 48 hours, respectively.

Moreover, in Control, T1, T2, T3 and T4 groups the HOS non-reacted sperm count $(\%)$ were significantly $(\mathrm{p}<0.01)$ lower at $0(23.75 \pm 1.44$, $26.13 \pm 1.15, \quad 31.19 \pm 1.67, \quad 21.69 \pm 0.72$ and $28.19 \pm 0.87$, respectively) as compared to 24 $(30.06 \pm 1.29,29.69 \pm 1.19,34.38 \pm 1.69,24.5 \pm 0.8$ and $31.56 \pm 0.91$, respectively), $36(33.81 \pm 1.1$, $34.00 \pm 1.29, \quad 37.63 \pm 1.64, \quad 27.81 \pm 0.71$ and $35.31 \pm 0.9$, respectively) and $48(38.5 \pm 0.99,38.63$ $\pm 1.4,40.94 \pm 1.6,31.5 \pm 0.93$ and $38.81 \pm 0.93$, respectively) hours post-chilling. Exceptionally, in $\mathrm{T} 1$ and T2 groups the HOS non-reacted sperm count were differ non-significantly between 0 and 24 hours of preservation time. Further, the HOS non-reacted sperm count recorded in various groups were also differed significantly $(\mathrm{p}<0.01)$ at 24, 36 and 48 hours post-chilling.

The corresponding overall mean value of HOST non-reacted sperm count $(\%)$ irrespective of preservation time was found significantly $(\mathrm{p}<0.01)$ lowest in T3 $(26.38 \pm 0.6)$ as compared to Control $(31.53 \pm 0.9)$, T1 $(32.11 \pm 0.85)$, T2 $(36.03 \pm 0.93)$ and $\mathrm{T} 4(33.47 \pm 0.67)$ groups. However, significantly $(\mathrm{p}<0.01)$ highest overall mean value of HOST non-reacted sperm count was noted in T2 among all the groups.

\section{DISCUSSION}

The findings of present study were in close agreement with the findings of Hamedani et al. (2016) who reported significantly $(p<0.05)$ higher values of HOS reacted sperm count in $3 \mathrm{mM}$ vitamin E supplemented $(80.60 \pm 0.40$ and $23.80 \pm 0.73 \%$, respectively) as compared to control (71.40 \pm 0.97 and $16.80 \pm 0.91 \%$, respectively) group in chilled as well as frozen-thawed semen. However, their findings regarding significantly $(\mathrm{p}<0.05)$ higher values of HOS reacted sperm count in $1 \mathrm{mM}$ $(80.20 \pm 0.20$ and $26.8 \pm 0.92 \%$, respectively) and $2 \mathrm{mM}(87.0 \pm 1.22$ and $34.6 \pm 2.01 \%$, respectively) vitamin E supplemented as compared to control (71.40 \pm 0.97 and $16.80 \pm 0.91 \%$, respectively) group in chilled as well as frozen-thawed semen was contrary to the present findings where we found, significantly $(p<0.05)$ lower values of overall HOS reacted sperm count in $2 \mathrm{mM}(63.97 \pm 0.93 \%)$ and non-significantly lower in $1 \mathrm{mM}(67.89 \pm 0.85 \%)$ vitamin E supplemented as compared to control $(68.47 \pm 0.9 \%)$ group.

However, Anghel et al. (2010) reported the significantly $(\mathrm{p}<0.05)$ higher value for HOST reacted sperm count $(55.00 \pm 1.65$ vs $49.75 \pm 2.6$ $\%$ ) in $1.0 \mathrm{mM}$ of vitamin E supplemented as compare to control group in cryopreserved Alpine buck semen. Likewise, Anghel and Zamfirescu (2010) also recorded a significantly $(\mathrm{p}<0.05)$ higher values for post thaw HOS reacted sperm count in $1 \mathrm{mM}$ vitamin $\mathrm{E}$ supplemented $(58.97 \pm 0.95$ vs $53.02 \pm 0.98 \%)$ as compared to control group in cryopreserved Merino Palas ram's semen during normal reproduction season (October - December 2009). Similarly, Kurmi et al. (2018) also reported a significantly $(\mathrm{p}<0.05)$ higher HOS reacted sperm count in $1 \mathrm{mM}$ $(52.26 \pm 0.15 \%)$ as well as $2 \mathrm{mM}(54.36 \pm 0.17 \%)$ vitamin E supplemented as compared to control $(50.42 \pm 0.18 \%)$ group in frozen-thawed Chhotanagpuri ram semen. Same way, Saraswat et al. (2012) studied the effect of vitamin E supplementation at $4.5 \mathrm{mM}$ concentration in tris 
based extender on cryopreserved Sirohi goat semen and reported significantly $(\mathrm{p}<0.05)$ higher values for HOST reacted sperm count in vitamin $\mathrm{E}$ supplemented $(13.00 \pm 0.67$ vs $11.10 \pm 0.89 \%)$ as compared to control group. The above findings were incompatible with the present findings as we found lower values of overall HOS reacted sperm count in $1 \mathrm{mM}$, $2 \mathrm{mM}$ and $4 \mathrm{mM}$ vitamin E supplemented as compared to control group.

\section{REFERENCES}

20th Livestock Census All India Report, 2019. Department of Animal Husbandry, Dairying India

Aitken RJ, Gordon E, Harkiss D, Twigg JP, Milne P et al., 1998. Relative impact of oxidative stress on the functional competence and genomic integrity of human spermatozoa. Biol Reprod, 59: 10371046, doi: 10.1095/biolreprod59.5.1037

Amirat L, Tainturier D, Jeanneau L, Thorin C, Gerard O et al., 2004. Bull semen in vitro fertility after cryopreservation using egg yolk LDL: A comparison with Optidyl®, a commercial egg yolk extender. Theriogenology, 61(5): 895-907, doi: 10.1016/S0093-691X(03)00259-0

Anghel A and Zamfirescu S, 2010. Role of antioxidant additives in the protection of the cryopreserved semen against free radicals. Rom Biotechnol Lett, 15(3): 33-41

Anghel A, Zamfirescu S, Dragomir C, Nadolu D, Elena S et al., 2010. The effects of antioxidants on the cytological parameters of cryopreserved buck semen. Rom Biotechnol Lett, 15(3): 26-32

Batool A, Mehboob K, Qadeer S, Ansari MS, Rakha BA et al., 2012. Effect of alpha-tocopherol acetate and ascorbic acid in extender on quality of zebu bull spermatozoa. Pak J Zool, 44(6): 1487-1491

Baumber J, Sabeur K, Tram V and Barry B, 2003. Reactive oxygen species promote tyrosine phosphorylation and capacitation in equine spermatozoa. Theriogenology, 60(7): 1239-1247, doi: 10.1016/ S0093-691X(03)00144-4

Bilodeau JF, Blanchette S, Gagnon C and Sirard MA, 2001. Thiols prevent $\mathrm{H}_{2} \mathrm{O}_{2}$-mediated loss of sperm motility in cryopreserved bull semen. Theriogenology, 56: 275-286, doi: 10.1016/S0093$691 \mathrm{X}(01) 00562-3$
In conclusion, the highest HOS reacted and lowest HOS non-reacted sperm count were found in treatment group supplemented with $3 \mathrm{mM}$ of vitamin $\mathrm{E}$ in tris egg yolk citrate extender entails the favourable effect of vitamin $\mathrm{E}$ for buck semen preservation at refrigeration temperature.

Conflict of interest: Authors declare that there is no conflict of interest regarding the present research work.

Foote RH, 2002. The history of artificial insemination: selection notes and notables. J Anim Sci, 80: 1-10

Hamedani MA, Tahmasbi AM, Naserian AA and Ahangari YJ, 2016. Evaluation of vitamin E on microscopic parameters of chilled and frozen stored ram semen. Der Pharma Chemica, 8(6): 16-22

Kurmi DJ, Sinha MP, Kumar R, Hazarika SB, Dewry RK et al., 2018. Effect of vitamin $\mathrm{E}$ on the quality of frozen ram semen. Theriogen Insight, 8(1): 39-43, doi: $10.30954 / 2277-3371.01 .2018 .7$

Michael A, Alexopoulos C, Pontiki E, HadjipavlouLitina D, Saratsis P et al., 2007. Effect of antioxidant supplementation on semen quality and reactive oxygen species of frozen-thawed canine spermatozoa. Theriogenology, 68(2): 204-212, doi: 10.1016/j.theriogenology.2007.04.053

Saraswat S, Jindal SK, Priyadharsini R, Ramachandran N, Yadav S et al., 2012. The effect of antioxidants supplementation to cryopreservation protocol on seminal attributes and sperm membrane characteristics in Sirohi goat. J Phys Pharma Adv, 2(1): 49-58

Tariq M, Khan MS, Shah MG, Nisha AR, Chhalgari MU et al., 2015. Exogenous antioxidants inclusion during semen cryopreservation of farm animals. J Chem Pharm Res, 7(3): 2273-2280

White IG, 1993. Lipids and calcium uptake of sperm in relation to cold shock and preservation: A review. Reprod Fertil Dev, 5: 639-658, doi: 10.1071/ RD9930639

ZhaoY and Buhr MM, 1995. Cryopreservation extenders affect calcium flux in bovine spermatozoa during a temperature challenge. J Androl, 16: 278-285, doi: 10.1002/j.1939-4640.1995.tb00526.x

Received - 27.09.2020, Accepted - 10.11.2020, Published - 01.12.2020 